\title{
KEPUASAN PERAWAT TERHADAP PELATIHAN SISTEM INFORMASI DALAM PROSES DOKUMENTASI ASUHAN KEPERAWATAN DI RSU IMELDA PEKERJA INDONESIA
}

\author{
Rani Damanik \\ Program Studi Ilmu Keperawatan, Universitas Sari Mutiara Indonesia \\ E-mail: rani140387@gmail.com
}

\begin{abstract}
System information is one of the attributes that are useful in relieving the documentation process in the treatment of a number of challenges while creating new documentation. The nursing process based information systems is aimed to manage patient records based on the needs of the patients, using design Visual Basic 6.0 (VB) and Microsoft SQL Server 2000 as the database link. The steps in the nursing process, such as: assessment, diagnosis formulation, intervention, implementation and evaluation of nursing, then in doing the nursing process standards covering all aspects of nursing is done through a system of classification as NIC, NOC, and NANDA. The purpose of this study was to identify the statisfaction of information systems in the process of documentation of nursing care in Imelda Hospital. The study design was quash experiment, the population was nurses in Jasmine Room of Imelda Hospital. The samples were 22 respondents, taken by using Cohen's $d$ formula, with a purposive sampling technique. The data were collected by using questionnaires and analyzed by paired sample t test. The test results showed that there were differences in effectiveness between before and after the application of information systems in the process of documentation of nursing care in a private hospitals in Medan with $p$-value $=0.00$ ( $p$ $<0.05)$ and $H a: \mu x 1 \neq \mu \times 2$ which indicated that $H_{a}$ was accepted and $H_{o}$ was rejected.
\end{abstract}

Keywords: Information system, nursing care documentation.

\begin{abstract}
Abstrak
Sistem informasi merupakan salah satu atribut yang bermanfaat dalam meringankan proses dokumentasi dalam perawatan sekaligus menciptakan sejumlah tantangan dokumentasi baru. Sistem informasi dalam proses asuhan keperawatan dengan menggunakan Visual Basic 6.0 (VB) and Microsoft SQL Server 2000 yang dihubungkan dengan database. Standar proses dokumentasi asuhan keperawatan NIC, NOC, dan NANDA dengan tahapan, penelitian ini adalah untuk mengidentifikasi kepuasan perawat pada pelatihan sistem informasi dalam proses dokumentasi asuhan keperawatan di Rumah Umum Imelda Pekerja Indonesia Medan. Tehnik pengambilan data menggunakan desain penelitian quasy experiment, dengan uji paired sample $t$ test. Populasi penelitian adalah perawat di Ruangan Melati Rumah Sakit Umum Imelda Pekerja Indonesia. Tehnik pengambilan sampel dilakukan dengan menggunakan rumus Cohen's $d$ melalui pendekatan purposive sampling maka diperoleh jumlah sample sebanyak 22 orang. Hasil penelitian yaitu ada perbedaan kepuasan perawat antara sebelum dan sesudah pelatihan sistem informasi dalam proses dokumentasi asuhan keperawatan di Rumah Sakit Umum Imelda Pekerja Indonesia dengan nilai $(p=0.00)$, sehingga $(p<0.05)$, dengan kata lain (Ha: $\mu x 1 \neq \mu x 2)$, maka Ha diterima dan Ho ditolak.
\end{abstract}

Kata kunci : Sistem informasi, dokumentasi asuhan keperawatan. 


\section{PENDAHULUAN}

Sistem informasi merupakan salah satu atribut yang bermanfaat dalam meringankan proses dokumentasi dalam perawatan sekaligus menciptakan sejumlah tantangan dokumentasi baru. Beberapa tahun terakhir, teknologi informasi telah diperkenalkan kepada keperawatan di banyak rumah sakit untuk mendukung tugas seharihari mereka. Perawat adalah kelompok pengguna akhir terbesar dalam Sistem Informasi Rumah Sakit. Para perawat yang menggunakan kertas diharapkan telah menggunakan komputerisasi dalam melakukan pengolah informasi untuk melakukan praktik keperawatan (Gavarand, Seremian \& Samadbeik, 2017).

Sistem informasi secara luas dianggap sebagai salah satu kunci dalam meningkatkan kualitas pelayanan kesehatan (Palvia, Lowe, Nemati, \& Jacks, 2014). Sistem informasi sebagai tempat penyimpanan data tentang semua kegiatan untuk mempromosikan, memulihkan atau mempertahankan kesehatan (Ramadhan, Ssenyonga, \& Sumil, 2014).

Penelitian yang dilakukan oleh Adegboyega dan Aniefiok (2014) tentang proses keperawatan yang berbasis sistem informasi yang bertujuan untuk melakukan pengelolaan catatan pasien yang didasarkan pada kebutuhan pasien yang dilakukan menggunakan desain Visual Basic 6.0 (VB) dan Microsoft SQL Server 2000 sebagai penghubung database. Hasil penelitian diperoleh bahwa $80 \%$ menunjukkan kemudahan dalam penggunaan data.

Hasil penelitian yang dilakukan oleh Jathanna (2017), tentang kesadaran dan persepsi perawat terhadap sistem informasi kesehatan di Rumah Sakit. Diperoleh hasil bahwa perawat sadar akan pentingnya sistem informasi dan mengadopsinya karena perawat merasakan manfaat dalam bidang kualitas dalam pengambilan keputusan. Diperlukan strategi untuk meningkatkan pengetahuan dalam penggunaan sistem informasi di kalangan perawat yang memiliki persepsi dan sikap negatif terhadapnya.

Hasil survey awal yang dilakukan oleh peneliti dalam penggunaan sistem informasi asuhan keperawatan di Rumah Sakit Umum Pusat Haji Adam Malik, Rumah Sakit Umum Imelda Pekerja Indonesia, Rumah Sakit Umum Herna Medan dan Rumah Sakit Umum
Santa Elisabeth Medan. Diperoleh bahwa Rumah Sakit Umum Santa Elisabeth Medan telah menggunakan sistem informasi dalam proses dokumentasi asuhan keperawatan.

Fenomena yang ada pada saat ini, masih terdapat beberapa rumah sakit yang sedang berupaya dalam memenuhi melaksanakan SIRS untuk meningkatkan efisiensi, efektifitas, profesionalisme, kinerja, serta akses dan pelayanan Rumah Sakit. Sistem informasi rumah sakit merupakan salah satu bagian dari asuhan keperawatan yang berbasis komputer. Pelaksanaan sistem informasi dalam proses dokumentasi asuhan keperawatan, diperoleh bahwa Rumah Sakit Umum Imelda Pekerja Indonesia belum melaksanakan sistem informasi dalam proses dokumentasi asuhan keperawatan. Berdasarkan hal tersebut peneliti tertarik untuk melakukan penelitian tentang efektifitas sistem informasi dalam proses dokumentasi asuhan keperawatan di Rumah Sakit Umum Imelda Pekerja Indonesia Medan.

\section{METODE PENELITIAN}

Penelitian menggunakan metode quasy experiment design yang bertujuan untuk mengetahui pengaruh satu variabel. Desain penelitian paired sample $t$ test dimana penelitian dilakukan pada satu kelompok subyek yang dilakukan perlakuan untuk mengidentifikasi kepuasan perawat sebelum dan sesudah. Penelitian dilakukan di di Rumah Sakit Umum Imelda Pekerja Indonesia ruangan Melati, pelaksanaan penelitian dilakukan pada bulan Mei sampai dengan Juni 2017.

Peneliti untuk mengetahui kepuasan sistem informasi dalam proses dokumentasi asuhan keperawatan di Rumah Sakit Umum Imelda Pekerja Indonesia ruangan Melati dengan populasi penelitian adalah perawat Rumah Sakit Umum Imelda Pekerja Indonesia ruangan Melati. Tehnik pengambilan sample dalam penelitian ini menggunkan rumus Cohen's $d$ melalui pendekatan purposive sampling yaitu sebanyak 22 orang dengan rincian 20 perawat pelaksana dan 1 orang kepala bidang keperawatan beserta 1 orang wakil kepala bidang keperawatan.

Instrumen sistem informasi dalam proses asuhan keperawatan yaitu: manusia, Visual Basic (VB), Microsoft SQL Server 2000, NIC, NOC, NANDA, format DepKes 
(2005), dan kuesioner The DeLone and McLean Model of Information Systems dengan nilai CVI expert=1. Nilai reliabilitas diperoleh dari 30 perawat di Rumah Sakit Umum Royal Prima yang memiliki tipe yang sama dengan rumah sakit yang dilakukan penelitian yaitu tipe $B$ diperoleh nilai Cronbach's Alpha 0.89 .

\section{HASIL PENELITIAN}

Tabel 1.

Data demografi perawat di RSU Imelda Pekerja Indonesia $(n=22)$

\begin{tabular}{|c|c|c|}
\hline \multirow{2}{*}{\multicolumn{3}{|c|}{$\begin{array}{ll}\text { No. } & \text { Data Demografi } \\
1 . & \text { Jenis Kelamin }\end{array}$}} \\
\hline & & \\
\hline Laki-Laki & 5 & 22.7 \\
\hline Perempuan & 17 & 77.3 \\
\hline Total & 22 & 100 \\
\hline 2. Usia & & \\
\hline 21-35 tahun & 10 & 45.5 \\
\hline $35-45$ tahun & 9 & 40.9 \\
\hline 45-60 tahun & 3 & 13.6 \\
\hline Total & 22 & 100 \\
\hline 3. Tingkat Pendidikan & & \\
\hline DIII Keperawatan & 7 & 31.8 \\
\hline S1 Keperawatan & 14 & 63.6 \\
\hline S2 Keperawatan & 1 & 4.6 \\
\hline Total & 22 & 100 \\
\hline 4. Lama Kerja & & \\
\hline Kompeten (2-3 & 5 & 22.7 \\
\hline tahun) & 10 & 45.5 \\
\hline Cakap (3-5 tahun) & 7 & 31.8 \\
\hline Ahli (lebih 5 tahun) & 22 & 100 \\
\hline Total & & \\
\hline
\end{tabular}

Sebelum sistem informasi dalam proses dokumentasi asuhan keperawatan

Gambar 1.

Format asuhan keperawatan RSU Imelda Pekerja Indonesia.

\section{ASUHAN KEPERAWATAN}

Nama $\quad: . . \quad$ Usia \& Jenis Kelamin : $\ldots(\mathrm{L} / \mathrm{P})$

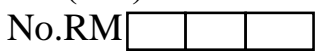

Dx Medis :

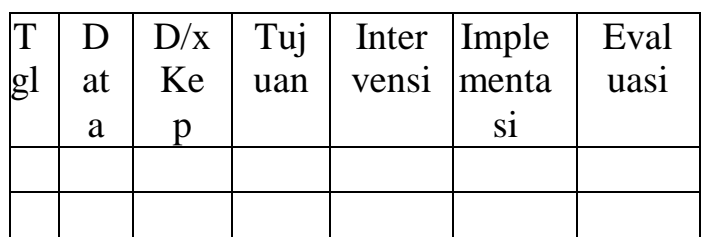

Sesudah sistem informasi dalam proses dokumentasi asuhan keperawatan

Sistem informasi dalam proses dokumentasi asuhan keperawatan telah didesain dengan menggunakan VB dan MSQL 2000, dapat dilihat sebagai berikut:

Gambar 2.

Pengkajian keperawatan sesudah sistem informasi.

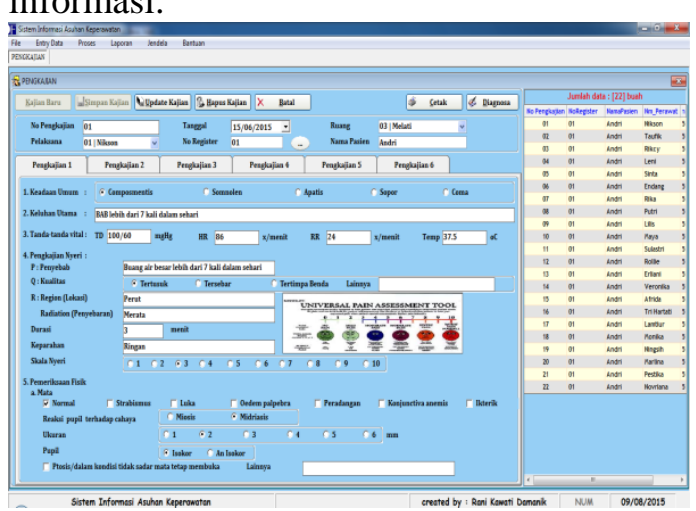

Gambar 3.

Diagnosa keperawatan sesudah sistem informasi.

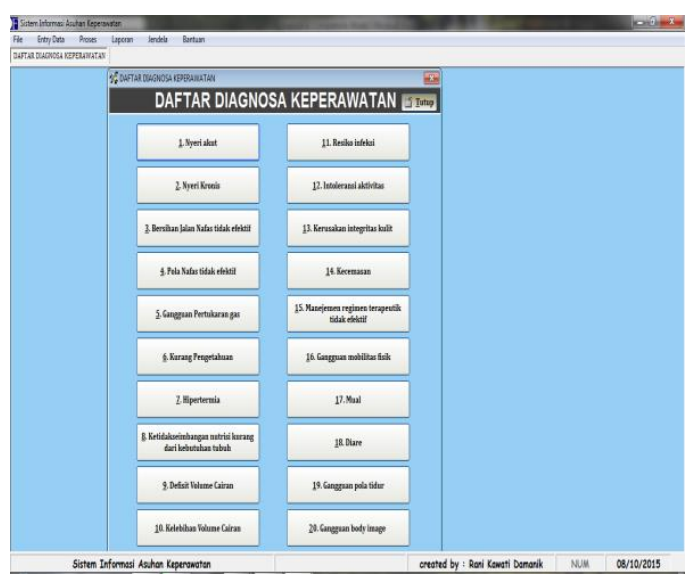

Gambar 4.

Intervensi dan implementasi keperawatan sesudah sistem informasi.

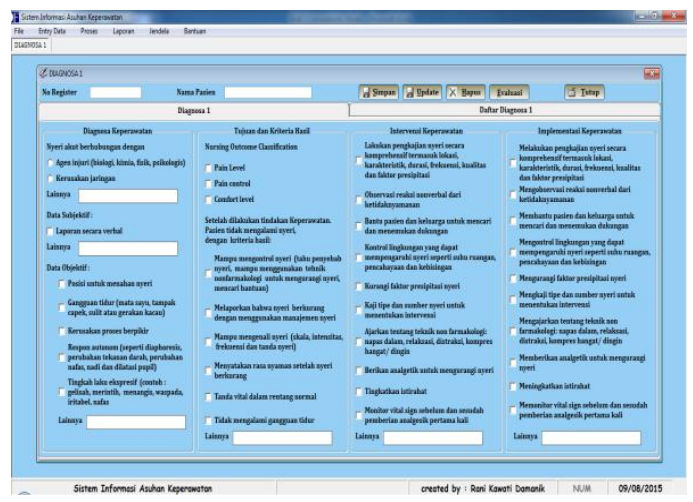

Sekolah Tinggi Ilmu Kesehatan (STIKes) Murni Teguh | 93 
Tabel 2.

Distribusi frekuensi sebelum dan sesudah sistem informasi di RSU Imelda Pekerja Indonesia $(\mathrm{N}=22)$.

\begin{tabular}{lccc}
\hline \multicolumn{1}{c}{$\begin{array}{c}\text { Variabel } \\
\text { penelitian }\end{array}$} & Mean & $\begin{array}{c}\text { Standar } \\
\text { Deviasi }\end{array}$ & $\boldsymbol{p}$ \\
\hline $\begin{array}{l}\text { Sebelum } \\
\text { pelatihan } \\
\text { sistem }\end{array}$ & 2.33 & 22 & \\
informasi & & & 0.00 \\
$\begin{array}{l}\text { Sesudah } \\
\text { pelatihan }\end{array}$ & 3.06 & 26 & \\
$\begin{array}{l}\text { sistem } \\
\text { informasi }\end{array}$ & & & \\
Selisih & 0.73 & 4 & \\
\hline
\end{tabular}

Gambar 5.

Evaluasi keperawatan sesudah sistem informasi asuhan keperawatan.

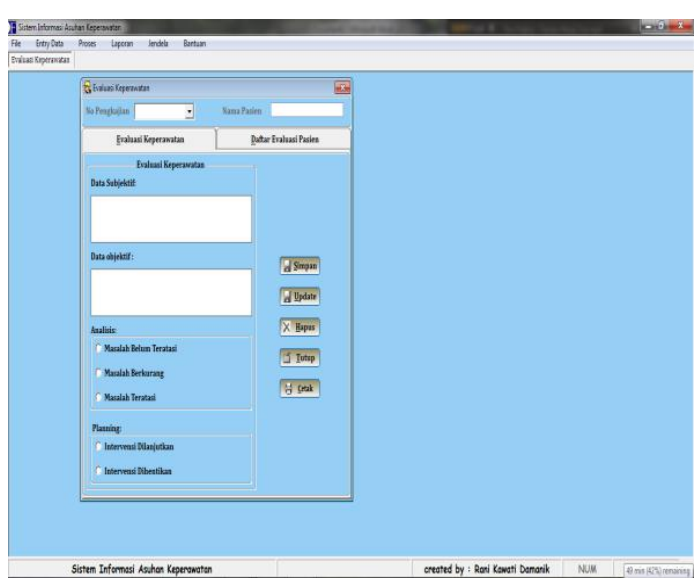

Gambar 6.

Print Out asuhan keperawatan.

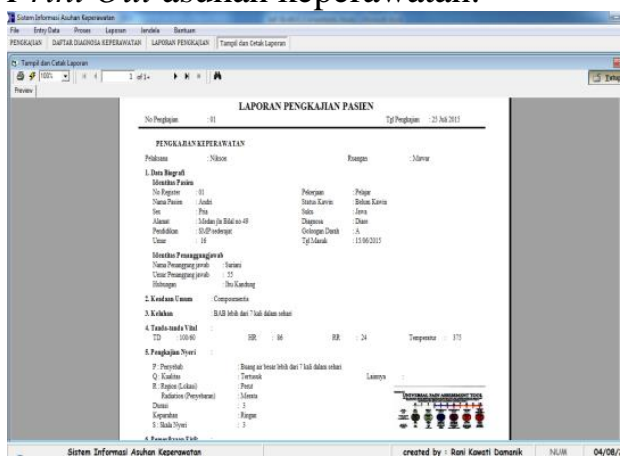

Sebelum dan sesudah sistem informasi dalam proses dokumentasi asuhan keperawatan.

Tabel 3. Hasil uji paired sample t test variabel penelitian $(\mathrm{N}=22)$.

\begin{tabular}{|c|c|c|c|}
\hline No. & Kategori & $\begin{array}{c}\text { Sebelum } \\
\text { Nilai } \\
\text { (persen) }\end{array}$ & $\begin{array}{c}\text { Sesudah } \\
\text { Nilai } \\
\text { (persen) }\end{array}$ \\
\hline \multirow[t]{4}{*}{1.} & $\begin{array}{l}\text { Kepuasan } \\
\text { perawat }\end{array}$ & & \\
\hline & Puas & $5(22.7)$ & $17(77.3)$ \\
\hline & Tidak puas & $17(77.3)$ & $5(22.7)$ \\
\hline & Total & $22(100)$ & $22(100)$ \\
\hline \multirow[t]{4}{*}{2.} & $\begin{array}{l}\text { Kemudahan } \\
\text { mengakses } \\
\text { Mudah }\end{array}$ & & \\
\hline & Tidak & $14(63.6)$ & $17(77.3)$ \\
\hline & mudah & $8(36.4)$ & $5(22.7)$ \\
\hline & Total & $22(100)$ & $22(100)$ \\
\hline
\end{tabular}

PEMBAHASAN

Kepuasan perawat sebelum sistem informasi dalam proses dokumentasi asuhan keperawatan

Dokumentasi bagian penting dari praktik keperawatan profesional, sehingga berbagai upaya perbaikan dilakukan secara global terhadap perbaikan mutu dokumentasi yang dilakukan secara terus-menerus. Perubahan dokumentasi sangat diperlukan, termasuk membangun kemampuan perawat yang kompeten dalam mengisi dokumentasi, melakukan desain yang menarik untuk memudahkan sipengguna dalam melakukan dokumentasi. Dokumentasi dengan sistem informasi merupakan salah satu solusi dalam meningkatkan dokumentasi keperawatan (Okaisu, Kalikwani, Wanyana, \& Coetzee, 2014).

Hasil penelitian yang dilakukan di Rumah Sakit Umum Imelda Pekerja Indonesia Medan diperoleh bahwa responden yang mengatakan kemudahan dalam mengakses data mengatakan mudah dalam mengakses data sebanyak 14 orang (36.6\%).

Berdasarkan penelitian yang dilakukkan oleh Adegboyega dan Aniefiok (2014), tentang efektifitas sitem informasi dalam proses dokumentasi asuhan keperawatan dengan berfokus pada teori Orlando yang dilaksanakan dengan menggunakan Visual Basic dan SQL. Sistem 
dievaluasi dengan menggunakan kuesioner terstruktur dalam mengukur kemudahan akses data, mencegah terjadinya duplikasi, dan meningkatkan kepuasan pengguna. Diharapkan dengan menggunakan sistem informasi yang telah didesain Visual Basic dan $S Q L$ dapat mendukung teori Orlando dalam membina hubungan yang dinamis antara perawat dengan pasien.

Beberapa penelitian dan tinjauan literatur yang ada, diperoleh bahwa terdapat kesenjangan dengan peneliti lakukan di Rumah Sakit Umum Imelda Pekerja Indonesia Medan. Hal ini disebabkan karena instrumen yang diisi oleh responden tidak mampu menggambarkan keadaan yang sebenarnya, meskipun peneliti sudah mengamati responden dalam mengisi kuesioner yang disebarkan, hal ini disebabkan karena lingkungan rumah sakit tidak kondusif dalam mengisi instrumen.

\section{Kepuasan sesudah sistem informasi dalam proses dokumentasi asuhan keperawatan}

Berdasarkan hasil penelitian yang dilakukan oleh Astarini (2018) tentang literatur review: efektivitas modifikasi dokumentasi keperawatan diperoleh hasil bahwa model dokumentasi asuhan keperawatan berbasis sistem informasi dapat meningkatkan kualitas dokumentasi asuhan keperawatan sehingga modifikasi pendokumentasian keperawatan sangat penting sehingga dapat memberi kemudahan bagi perawat dalam melakukan dokumentasi keperawatan.

Hasil penelitian sesudah sistem informasi diperoleh bahwa responden yang mengatakan dokumentasi responden mengatakan lengkap sesudah sistem informasi sebanyak 15 orang (68.2\%), kemudian perawat puas sebanyak 17 orang $(77.3 \%)$. Berdasarkan kemudahan dalam mengakses data diperoleh mudah dalam mengakses data sebanyak 17 orang $(77.3 \%)$.

Berdasarkan penelitian yang dilakukan oleh Adegboyega dan Anifiok (2014), tentang sistem manajemen dalam proses keperawatan dengan menggunakan teori Orlando diperoleh bahwa dengan sistem informasi dirancang dapat memudahkan para perawat untuk mengakses data keperawatan, mencegah pengulangan, meningkatkan akurasi dokumentasi atau kelengkapan dokumentasi yang dilakukan.
Beberapa penelitian dan tinjauan literatur yang ada, tidak terdapat kesenjangan dengan penelitian yang dilakukan sesudah sistem informasi. Berdasarkan hasil yang uji kuesioner yang dilakukan setelah diberikan simulasi dan workshop asuhan keperawatan yang telah didesain oleh peneliti. Diperoleh hasil penelitian bahwa dengan sistem informasi maka responden mengatakan ada item pilihan pengkajian hingga evaluasi keperawatan, sehingga meningkatkan kelengkapan dokumentasi, kemudahan akses, menghindari pengulangan dokumentasi atau duplikasi, dan meningkatkan kepuasan perawat dalam melakukan dokumentasi keperawatan.

\section{Kepuasan sebelum dan sesudah sistem informasi dalam proses dokumentasi asuhan keperawatan}

Transisi dari dokumentasi kertas ke dokumentasi berbasis komputer salah satu langkah mudah, sehingga komponen sistem dokumentasi dalam perawatan pasien up to date. Hasil penelitian yang dilakukan di Rumah Sakit Imelda Pekerja Indonesia di ruangan Melati yang dilakukan pada 22 orang perawat dengan menggunakan desain paired sample $t$ test untuk mengukur efektifitas sebelum dan sesudah sistem informasi dalam proses dokumentasi asuhan keperawatan diperoleh nilai mean sebelum 2.33 dan mean sesudah 3.06, sehingga diperoleh selisih 0.73 , berdasarkan nilai standar deviasi diperoleh nilai standar deviasi sebelum 22 dan nilai standar deviasi sesudah 26, sehingga selisih nilai standar deviasi 4 . Berdasarkan dari nilai signifikan $(p=0.00)$, sehingga $(p<0.05)$ maka penelitian ini menunjukkan bahwa terdapat perbedaan efektifitas sebelum dan sesudah sistem informasi dalam proses dokumentasi asuhan keperawatan.

Dukungan agar menggunakan catatan kesehatan elektronik untuk peningkatan informasi perawatan. Informasi yang diberikan yang berfokus pada pasien dan meningkatkan keselamatan pasien. Sistem informasi kesehatan tidak menambah beban, meningkatkan dokumentasi, dan tidak akan menghapus pekerjaan keperawatan yang sebelumnya, meningkatkan perlindungan pasien, komunikasi, mengurangi biaya (Shabnum, Afzal, Hussain \& Gilani, 2017). 
Adopsi dokumentasi keperawatan yang berbasis elektronik, merupakan salah satu peranan penting untuk keperawatan. Sistem informasi secara fundamental mengubah lingkungan praktek klinis berbasis sistem informatika untuk memberikan dokumentasi keperawatan yang relevan dengan keadaan sebenarnya atau tidak terjadi pengulangan, tahan lama, dan dirancang dengan baik untuk memenuhi kebutuhan perawat yang sibuk (Crystal \& Seckman, 2014).

Berdasarkan literatur dan penelitian terdahulu, bahwa terdapat beberapa manfaat yang diperoleh dengan menggunakan sistem informasi asuhan keperawatan. Sistem informasi asuhan keperawatan dapat memberikan manfaat kepada perawat untuk mempermudah perawat dalam melakukan proses dokumentasi asuhan keperawatan. Diharapkan dengan sistem informasi dalam proses dokumentasi asuhan keperawatan dapat meningkatkan kontribusi perawat dalam menyelesaikan tugas.

\section{KESIMPULAN}

Berdasarkan hasil analisis data dan pembahasan hasil penelitian mengenai kepuasan kepuasan perawat pada pelatihan sistem informasi dalam proses dokumentasi asuhan keperawatan di Rumah Umum Imelda Pekerja Indonesia Medan dengan nilai signifikan $(p=0.00)$, sehingga $(p<0.05)$, maka Ha diterima dan Ho ditolak, maka dapat disimpulkan bahwa ada perbedaan kepuasan antara sebelum dan sesudah pelatihan sistem informasi dalam proses dokumentasi asuhan keperawatan setelah diberikan sosialisasi, workshop dan simulasi sistem informasi dalam proses dokumentasi asuhan keperawatan.

\section{SARAN}

Bagi pendidikan keperawatan disarankan untuk mengadakan sosialisasi, workshop dan simulasi sistem informasi dalam proses dokumentasi asuhan keperawatan sehingga pendidikan keperawatan semakin berkembang.

Bagi praktik keperawatan disarankan, supaya menerapkan sistem informasi di praktik keperawatan yang ada dan menyediakan sarana pendukung seperti perangkat computer, jaringan internet dan perangkat lainnya yang mendukung penerapan sistem informasi dalam keperawatan di praktik keperawatan sehingga, lebih memudahkan perawat dalam memberikan asuhan keperawatan dan meningkatkan mutu asuhan keperawatan.

Bagi penelitian selanjutnya disarankan agar melakukan penelitian lebih lanjut dengan menggunakan asuhan keperawatan 13 domain NIC NOC NANDA kemudian menggunakan lembar observasi dan variabel kontrol dalam penilaian keefektifan sistem informasi dalam proses asuhan keperawatan, dengan menggunakan desain penelitian action research.

\section{REFERENSI}

Adegboyega, A., \& Aniefiok, J. A. (2014). Orlando nursing process based healthcare information management system. American Journal of Software Engineering and Applications, 3, 4753. Doi: 10.11648

Astarini, A. I. M. (2018). Literatur review: efektivitas modifikasi dokumentasi keperawatan. Jurnal Ners LENTERA, $6,(1), 42-48$.

Gavarand, A., Seremian, M \& Samadbeik, M. (2018). Information Processing in Nursing Information Systems: An Evaluation Study from a Developing Country, Iranian journal of nursing and midwifery research, 22 (5), 337382. DOI: 10.4103 .

Jathanna, R. (2017), Awareness and Perception of Nurses Towards E Health Records: A Hospital Study. Free Online Journal, 16 (2), 1-4.

Mugo M. D., \& Nzuki, D. (2014). Determinants of electronic health in developing countries. Journal International of Arts and Commerce, 3, 49-60.

Okaisu, E.M., Kalikwani, F., Wanyana, G. \& Coetzee, M. (2014). Improving the quality of nursing documentation: An action research project. Journal Information Technology Issues in Health Care, 38 (1), 1251-1262. Doi 10.4102.

Palvia, P., Lowe, K., Nemati, H., \& Jacks, T. (2014). Information technology issues in health care: hospital CEO and CIO perspectives. Journal Information 
Technology Issues in Health Care, 30 (1), 294-312.

Ramadhan, B. M., Ssenyonga, T., \& Sumil, R. N. (2014). Development and implementation of patient management information system of Kampala International University Teaching Hospital (KIU-TH), Bushenyi District, Uganda. An Open Access International Journal, 4, 7783.

Rojas, L. C., \& Seckman, A. C. (2014). The informatics nurse specialist role in electronic health record usability evaluation, Journal Computers Informatics Nursing, 32 (5), 214-220.

Shabnum. S., Afzal. M., Hussain. M., \& Gilani, A.S. (2017). Nursing Perceptions of Electronic Documentation. Saudi Journal of Medical and Pharmaceutical Sciences, 3, (8), 926-935. DOI: 10.21276. 